\title{
LEARNING THE ROPES: Measuring Renin: a long way from bioassasys to current standardization
}

\author{
JOEL MÉNARD
}

Université de Paris, Faculté de Médecine Paris-Descartes

Paris, France

DOI: $10.30824 / 2112-5$

Measuring renin in plasma has been a long-term dream, as soon as it was known that renin was liberated from the kidneys in proportion to the decrease in perfusion pressure. To achieve this goal, plasma renin measurements were established through measurement of renin's enzymatic activity to produce angiotensin I (Ang I) from plasma angiotensinogen in vitro (PRA) and to investigate its variations under different physiological and pathological conditions $s^{1,2}$. The detailed molecular mechanism underlying this step is better known since the crystal structures of glycosylated human angiotensinogen and renin and their interaction have been revealed.

At a late stage of 50 years of methodological research, investigators directly involved in laboratory measurements have collectively written a general review on all technical matters ${ }^{3}$. They discussed the difference between the enzymatic assay, PRA, and plasma renin concentration (PRC), and the so-called ponderal assay. i.e., the quantification of the active and total renin molecules circulating in plasma by a sandwich assay using pairs of monoclonal antibodies directed towards different epitopes of the protein.

Different methods of in vitro activation of the enzymatic activity of renin and some specific monoclonal antibodies which recognize total renin make it possible to investigate plasma active renin, total renin, and, by difference, prorenin. This inactive precursor of renin biosynthesis in the juxtaglomerular apparatus of the kidney and in other organs outside the kidney, such as the eye, is present in plasma at much higher concentration. Because of the possibility of an artificial ex-vivo activation or an interference with renin inhibitors, the exact conditions of blood sampling and plasma storage are of utmost importance $e^{3,4}$.

The main methodological issues are the following:

1) The in vitro production of Ang I by renin is dependent on renin's unique substrate species specificity (with an advantage of sheep substrate for human renin). It is

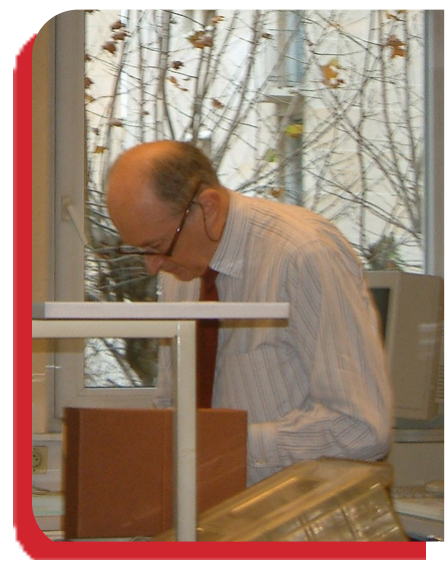

proportional to active plasma renin and is influenced by the level of angiotensinogen of hepatic origin present in the plasma with a concentration near the $\mathrm{Km}$ (Michaelis Constant) of the enzymatic reaction and is modestly influenced by the genotype. Angiotensinogen is high during pregnancy and synthetic estrogen therapy and low during congestive heart failure or renin-angiotensin system (RAS) inhibition in conjunction with diuretics.

2) Ang I has to be protected from its in vitro destruction by angiotensinases in proportion to the incubation time selected for the enzymatic reaction. Up to 1970, Ang I was measured by a pressor assay in anesthetized binephrectomized rats. From 1970 to 1985, radioimmunoassays with high specificity and sensitivity were developed followed by immuno-enzymatic assays in different systems which eliminate the use of radioactivity and allow to perform large series of determinations at the same time with the appropriate internal standards. Separation of angiotensin peptides was later-on performed by high performance liquid chromatography and further by liquid chromatographytandem mass spectrometry. Multiple degradation peptides of angiotensins were separately measured in vivo and in vitro ${ }^{5}$.

A complementary and necessary information was given by the appropriate measurement of a main final product of the system, angiotensin II (Ang II) after immediate inhibition of its production and degradation during blood sampling ${ }^{6}$. PRA levels are always highly correlated with plasma Ang II levels. The slope of correlation is influenced by any decrease (flatter slope) or increase (steeper slope) of plasma angiotensinogen and, in a practical way, renin assays are easier to perform than Ang II assays.

The first period of PRA measurements between 1960 and 1975, based on bioassays, provided important information on the influence of age, day-night cycle, posture, sodium content of the diet, menstrual cycle, specific effects of antihypertensive drugs and other conditions which can influence renin levels. Individuals 
have been defined as having low, normal or high levels of plasma renin within a continuous distribution of values $^{1,2}$. Micromethods of renin activity measurement were established in many animal species to study renin release in experimental hypertension. They detected renin outside the juxtaglomerular apparatus of the kidney, in the central nervous system, blood vessels, or the adrenal gland. The sensitivity and specificity of the methodology has a major influence on the results and their interpretation as it happens to be also for other techniques of renin measurement (western, northern and Southern blots for proteins, RNA and DNA) ${ }^{7}$. The putative presence and function of local RAS is still controversial, especially at the level of the brain. Similar controversies have concerned the extrarenal actions of aldosterone and the possibilities of its extra-adrenal production at the vicinity of its receptors.

Two original examples of the use of some poorly known advantages of enzymatic and other renin measurements are selected. A first example is given when total plasma renin is captured by a monoclonal antibody which immobilizes renin (prorenin and active renin) and allows for quantification by polyclonal antibodies linked to another epitope, located against the active site to measure active renin or, at another site, to measure at the same time active renin and prorenin (total renin) ${ }^{8}$. A group from Glasgow has measured the reactive rise in plasma renin concentration during the first-to-man administration of their $\mathrm{H} 142$ renin inhibitor in accordance with previous experimental results ${ }^{9,10}$. Inhibition of the enzymatic property of renin precisely correlated with the rise in active renin from renal origin, followed by a liberation of its intracellular precursor, prorenin.

A useful example of the species specificity of the reninangiotensin system was given by first investigations in transgenic hypertensive rats. This experimental model was initially considered a low renin model aiming to decipher the potential role of extra-renal renin in the pathogenesis of hypertension. By selecting different $\mathrm{pHs}$ for in vitro renin measurements, it was possible to separate in the Ang II excess, which characterizes the model, the predominant role of the transgenic mouse renin (optimal enzymatic reaction at $\mathrm{pH} 8.5$ ), from its feed-back to lower the native rat renin ( $\mathrm{pH}$ 6.5). By this, it was demonstrated that the model, initially described as low-renin, was indeed a high-mouse renin and a low rat-renin model with an equilibrium between the two systems ${ }^{11,12}$.
In 2020, the time of home-made renin assays was gone. Today, various chemoluminiscence assays with high output are used for multiple hormonal systems. Their intra-assay and inter-assay coefficient of variations are below $10 \%$. It is desirable to have renin results within three hours for the diagnosis of secondary hypertension and to monitor plasma renin during treatment, especially to monitor the sodium balance when diuretics and anti-aldosterone drugs are used as a monotherapy. By different mechanisms, beta-blockers decrease plasma renin, and blockers of the RAS increase it. Dihydropyridine type calcium channel blockers are rather neutral on plasma renin.

The optimal clinical information of plasma active renin can be obtained either by an Ang I enzymatic assay or an immunoenzymatic assay. Less frequently, both active renin and prorenin are measured, but the extra-renal origin of prorenin makes it difficult to interpret values, for instance when they are increased in diabetic patients. It is useful, and even mandatory, to detect secondary hypertension in the check-up of every individual with newly discovered permanent hypertension, who will have a follow-up of several decades. It is logical to simultaneously measure plasma aldosterone but the popular renin/aldosterone ratio, which has been widely promoted, is more a mnemotechnic than a reasonable tool.

The demonstration of unilateral disease by plasma renin measurements in the renal veins has been, and still should be, a major indication to investigate renal artery stenosis, renal infarctions, renin-secreting tumors and some renal and extrarenal cancers ${ }^{13}$. The results of the Cardiovascular Outcomes in Renal Athero-sclerotic Lesions (CORAL) study result did not encourage an agressive attitude on renal arteries to improve the global cardiovascular prognosis ${ }^{14}$ but the renal problem persists, and a case by case analysis aiming to retard renal insuficiency includes renin measurements in renal veins in conjunction with other hemodynamic and isotopic investigations.

\section{Suggestions}

Any person, who has a recently discovered permanent high blood pressure, could benefit once in life from a renin- and aldosterone measurement measured under optimal conditions, before being labelled as hypertensive and treated for several decades. The shorter the time to obtain and analyze the results between clinic, laboratory and clinic, the easier will be the practical use of plasma 
renin and aldosterone measurements ${ }^{15}$. Evaluating each parameter separately is more informative than the simplified memorization of an aldosterone/ renin ratio with an arbitrary threshold within a continuous distribution.

The use of fixed-dose combination therapies, as recommended today by hypertension guidelines, minimizes the advantage of the «low and high renin " classification, initially proposed by John Laragh, to make the choice of a full-dose of monotherapy between diuretics (low renin) or beta-blockers and renin-angiotensin inhibitors (high renin). Plasma renin measurements are already used to follow the magnitude of sodium depletion during the medical treatment of primary aldosteronism by an anti-aldosterone drug. Information on the results, which could be expected from a systematic monitoring of renin and aldosterone measurements at the different dosages of these fixed-dose combinations, could be useful to interpret treatment results at different sodium intakes in conjunction with blood pressure changes. The renin methodology requires to be well controlled at the clinic during blood sampling and in the laboratory. Proper use as a routine will certainly confirm previous research contributions to clinical care.

\section{REFERENCES}

1. Genest J, Boucher R, De Champlain J, et al. Studies on the renin-angiotensin system in hypertensive patients Can Med Assoc J 1964; 90(4):263-8

2. Brown JJ, Davies DL, Lever AF, Roberson JIS. Variations in plasma renin concentration in several physiological and pathological states. Can Med Assoc J 1964 Jan 25; 90(4):201-6.

3. Campbell DJ, Nussberger J, Stowasser M, et al. Activity assays and immunoassays for plasma Renin and prorenin: information provided and precautions necessary for accurate measurement. J.Clin Chem. 2009; 55(5):867-77.

4. Sealey JE. Plasma renin activity and plasma prorenin assays. Clin Chem. 1991; 37(10 Pt 2):1811-9.

5. Guo Z, M. Poglitsch, B. C McWhinney, J. et al. Measurement of Equilibrium Angiotensin II in the Diagnosis of Primary Aldosteronism. Clin Chem 2020; 66:483-492.

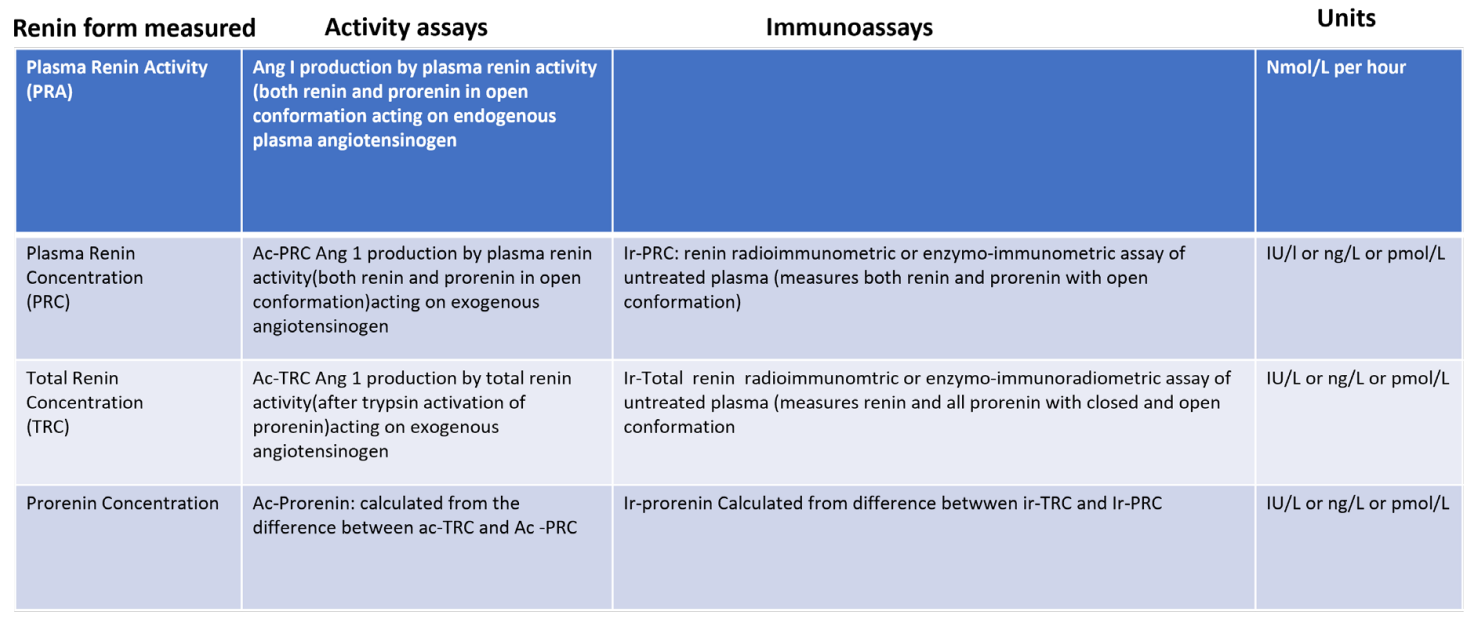

Activity assays (ac-PRC, ac-TRC, ac-prorenin) can be calibrated against the International Reference Preparation of human renin, and results are expressed in international units per liter [Bangham et al. Clin Sci Mol Med Suppl 1975;2:135s-159s]. ir-TRC can be measured by 2 methods :by immunoassay with a pair of antibodies that recognize both renin and prorenin, or by renin immunoassay after trypsin activation of prorenin or after conversion of prorenin to an open conformation by incubation with a renin inhibitor. Modified from DJ Campbell et al. Clinical Chemistry 55:5 867-877 (2009) 
6. Nussberger J, Brunner DB, Waeber B, Brunner HR. Specific measurement of angiotensin metabolites and in vitro generated angiotensin II in plasma. Hypertension. 1986; 8:476-82.

7. Jin $M$, Wilhelm MJ, Lang RE, Unger T, Lindpaintner $K$, Ganten D. Endogenous tissue renin-angiotensin systems. From molecular biology to therapy. Am J Med. 1988; 84:28-36.

8. Ménard J, Bews J, Heusser C. A multirange ELISA for the measurement of plasma renin in humans and primates. J Hypertens Suppl. 1984; 2:S275-8.

9. Webb DJ, Manhem PJ, Ball SG, Inglis G, Leckie BJ, Lever AF, Morton JJ, Robertson Jl, Murray GD, Ménard J, et al. A study of the renin inhibitor H142 in man. J Hypertens. $1985 ; 3: 653-8$.

10. Hofbauer KG, Wood JM, Gulati N, Heusser C, Ménard J. Increased plasma renin during renin inhibition. Studies with a novel immunoassay Hypertension.1985;7:161-5.

11. Bachmann S, Peters J, Engler E, Ganten D, Mullins J. Transgenic rats carrying the mouse renin gene--morphological characterization of a low-renin hypertension model. Kidney Int.1992; 41:24-36.

12. Bohlender J, Ménard J, Edling O, Ganten D, Luft FC. Mouse and rat plasma renin concentration and gene expression in (mRen2) 27 transgenic rats. Am J Physiol. 1998; 274(5):H1450-6.

13. Gaudemar M, P. Bruneval, J P Camilleri. Tumor syndromes with inappropriate renin secretion. Diagnostic criteria and review of published cases. Ann Pathol 1988; 8:83-9018.

14. Cooper CJ, Murphy TP, Cutlip DE, Jamerson K, Henrich W, Reid DM, Cohen DJ, Matsumoto AH, Steffes M, Jaff MR, Prince MR, Lewis EF, Tuttle KR, Shapiro Jl, Rundback JH, Massaro JM, D'Agostino RB Sr, Dworkin LD, CORAL Investigators. Stenting and medical therapy for atherosclerotic renal artery stenosis. N Engl J Med. 2014; 37013-22.

15. Morimoto R, Ono Y, Tezuka Y, Kudo M, Yamamoto S, Arai T, Gomez-Sanchez CE, Sasano H, Ito S, Satoh F. Rapid Screening of Primary Aldosteronism by a Novel Chemiluminescent Immunoassay. Hypertension. $2017 ; 70: 334-341$

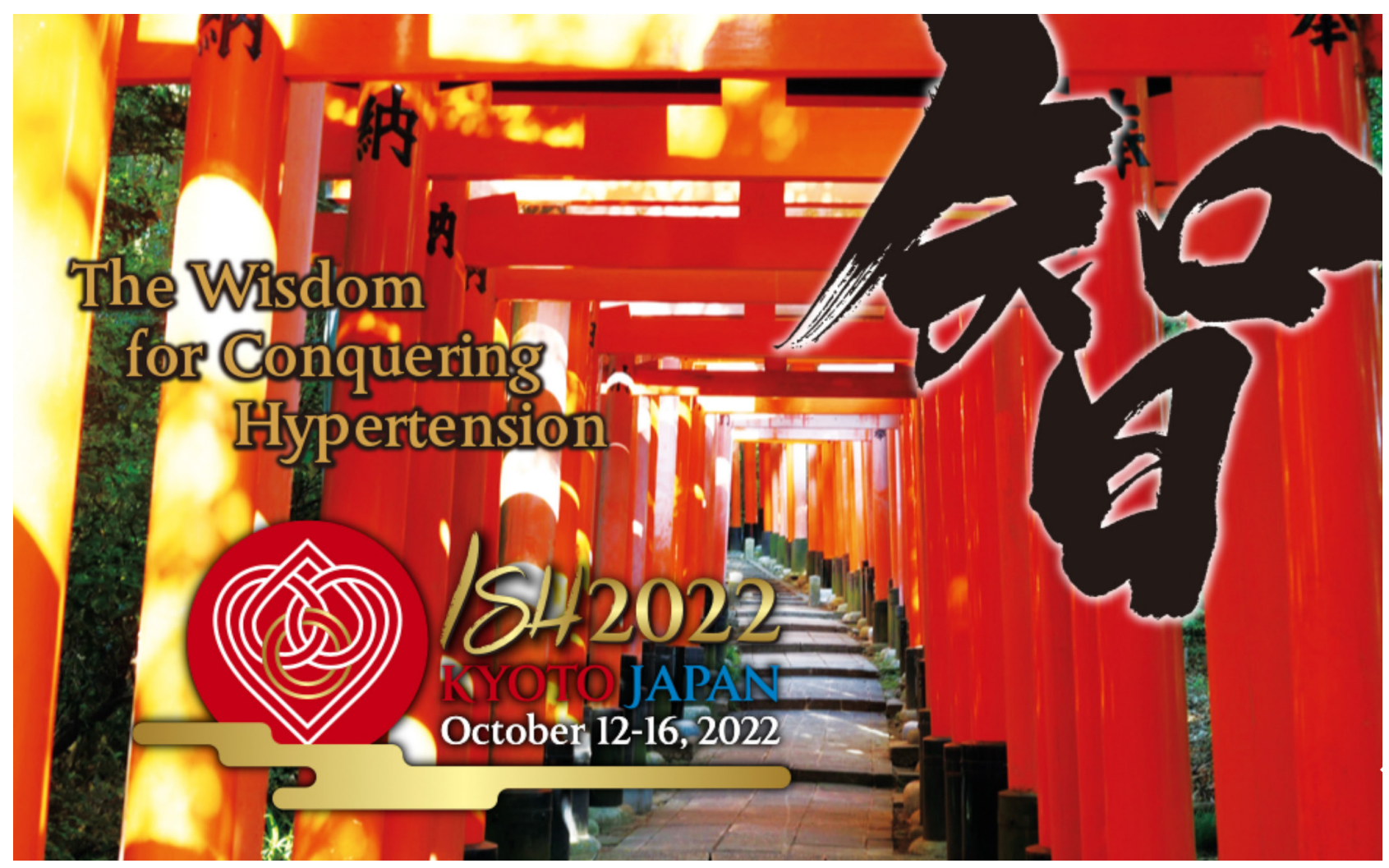

